\title{
Open-vessel microwave-promoted Suzuki reactions using low levels of palladium catalyst: Optimization and scale-up
}

Nicholas. E. Leadbeater, ${ }^{a, *}$ Victoria A. Williams, ${ }^{a}$ Thomas M. Barnard ${ }^{b}$ and Michael J. Collins Jrb

a) Department of Chemistry, University of Connecticut, Unit 3060, 55 North Eagleville Road, Storrs, CT 06269-3060, USA

b) CEM Microwave Technology, 3100 Smith Farm Road, Matthews, NC 28104, USA

nicholas.leadbeater@uconn.edu

\section{SUPPORTING INFORMATION}

Images of the open-vessel microwave apparatus used

pages S2-S4 
Figure 1: Monomode microwave apparatus used for reactions on a $5 \mathrm{mmol}$ scale

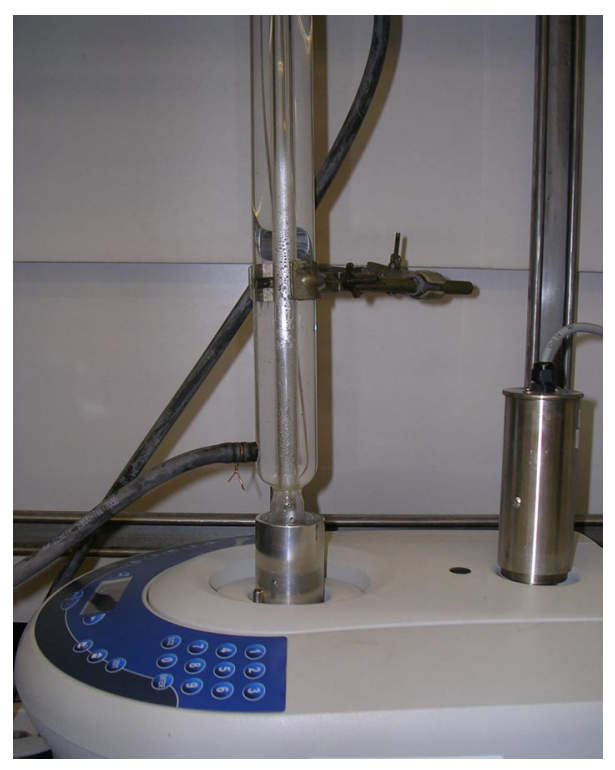

page S2 
Figure 2: Multimode microwave apparatus used for reactions on a $1 \mathrm{~mol}$ scale

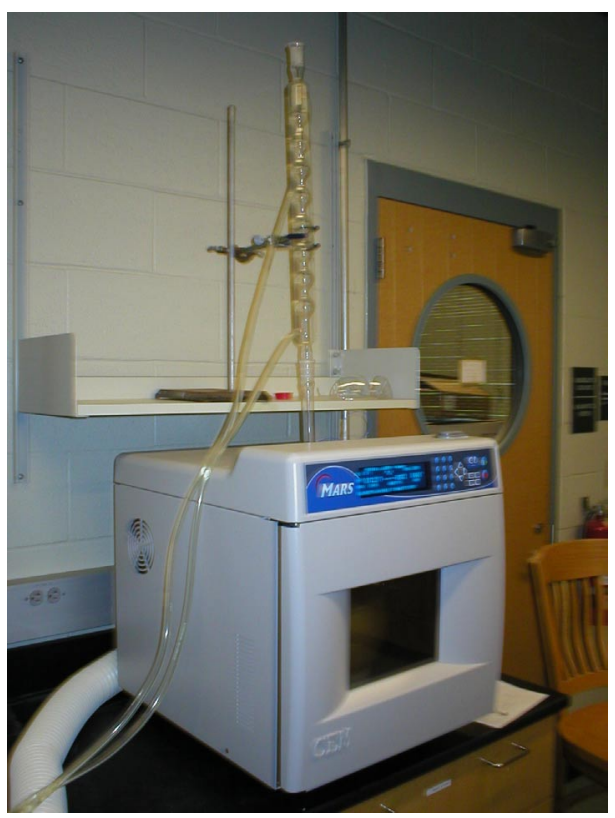

page S3 
Figure 3: Adaptor used for reactions on a 1 mol scale with overhead stirring

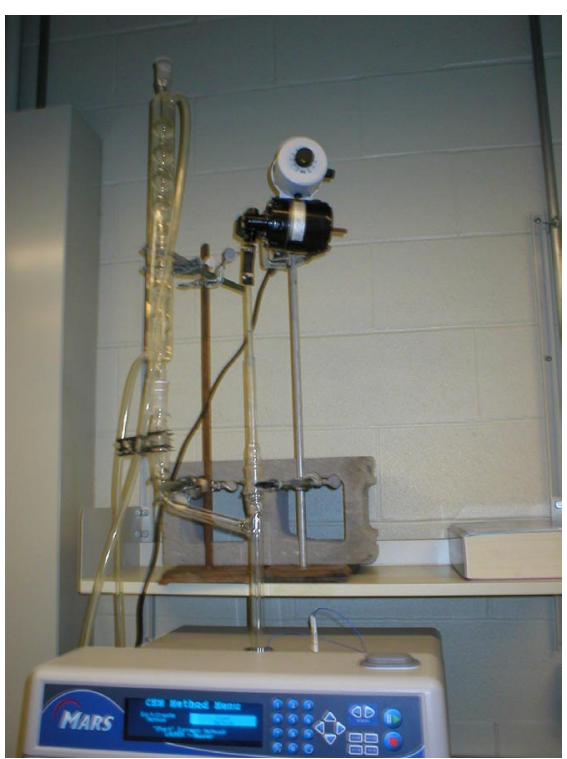

